PIAGET, J. On the concept of memory and identity. Barre, Mass.: Clark University Press, 1968.

TANNER, J., \& INHELDER, B. (Eds.), Discussions on child development. Vol. 4. New York: International Universities Press, 1960.

NOTES

1. This work was supported in part by a grant to the MINNEMAST Center at the University of
Minnesota from the National Science Foundation (GE-3), and in part by grants to the University of Minnesota Center for Research in Human Learning from the National Science Foundation (GS-1761) the National Institute of Child Health and Human Development (HD-01136-04), and from the Graduate School of the University of Minnesota

2. Johnson, P., \& Murray, F. A framework for the analysis of the child's concept of weight. Submitted for publication, 1969.

\title{
The effects of stimulus hue on backward masking under conditions of monoptic and dichoptic stimulus presentation
}

\author{
LEON W. TEFT, University of Bridgeport, \\ Bridgeport, Conn. 06602
}

Stimulus hue is a significant variable in visual backward masking when target and mask figure-ground brightness contrast is eliminated. Target stimulus hues are ordered from blue, red, green, to yellow in terms of their resistance to masking by hue. A similar ordering was found for masking stimulus hues in terms of their average inhibiting effect on all target stimuli. Significantly more masking occurred under dichoptic conditions of stimulus presentation.

In general, backward masking refers to the inhibition of the perception of a test stimulus when this stimulus is followed in close temporal succession and spatial proximity by a masking stimulus. Many investigators have explored backward masking in the visual modality and have attempted to define the parameters of this phenomenon. Excellent reviews of masking research have been provided by Raab (1963) and Alpern (1952). Taking as their measure of backward masking the difference in test stimulus detection thresholds under conditions of the presence and absence of a masking stimulus, investigators have found masking effects to be a function of the type of stimulus employed (Schiller, 1965), i.e., light flash or pattern; stimulus intensity (Kolers, 1962); duration of interstimulus interval (Eriksen \& Hoffman, 1963), and mask (Alpern, 1953); spatial proximity of test and mask stimulus contours (Werner, 1935); and method of stimulus presentation (Schiller \& Wiener, 1963), i.e., monoptic (both stimuli to the same eye) and dichoptic (the two stimuli to different eyes). This list of parameters, while not exhaustive, represents the major focus of research in this area.

The aim of the present experiment was to explore the effects of another stimulus dimension, viz hue, in the backward masking paradigm. Baroncz observed chromatic masking with colored flashes of light; however, the effect was found to be highly dependent upon the utilization of a narrow range of interstimulus intervals (Alpern, 1952). Werner (1935) in his classic study of contour formation reported chromatic masking with selected colors and backgrounds. The findings of these two experiments point to hue as a significant variable in backward masking; however, it is to be noted that in both experiments the effect of hue was confounded with brightness contrast between figure and background. Another deficiency of these experiments was the failure of the investigators to report in quantitative terms the stimulus specifications. The present experiment was designed to overcome these deficiencies by systematically varying target and mask hue relations in a quantitative paradigm. In addition, the experimental design employed monoptic and dichoptic stimulus presentation to yield data on the relative contributions of central and peripheral mechanisms to the masking effect.

\section{METHOD}

Stimuli were presented in a specially designed seven-field tachistoscope driven by a Scientific Prototype Modified Model 1B three-channel timer. The use of a split-field balanced optical system permitted the monoptic or dichoptic exposure of stimuli. Identity of hue and brightness in the six stimulus fields (excluding the fixation field) was accomplished by including in all stimulus fields an equal number of reflection and transmission Inconel coated 30\%-30\% mirrors. The light source for each field consisted of two cold cathode mercury vapor argon lamps coated with magnesium and tungstate phosphor. The maximum rise and fall of the lamps was rated at $2.5 \mathrm{msec}$. The target stimuli were four sets of 18 letters of the alphabet (E, F, G, I, N, O, R, and V were omitted). The letters were $3 / 4$-in. block cut from Munsell notations 5R 5/4, 5G 5/4, $5 Y 5 / 4$, and $5 B 5 / 4$. Each of the letters was

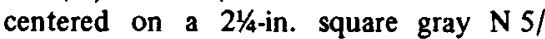
background. This background was used to eliminate brightness contrast between figure and background. The four masking stimuli consisted of a 1-1/8-in. square lattice pattern cut from the four Munsell hues. The masking stimuli were mounted on a $2 \frac{1}{4}$-in. square N 5/ background. Ss looking through the viewing eyepiece saw a $5 \times 8$ in. homogeneous white fixation field at a brightness of $1.1 \mathrm{ft}-\mathrm{L}$. Ss were instructed to center their gaze on the central portion of the fixation field. The stimulus fields were masked down to a $2 \frac{1}{4}$-in. square and subtended a visual angle of $2.5 \mathrm{deg}$. The target and masking figures subtended visual angles of .9 and $1.3 \mathrm{deg}$, respectively. All target and mask fields were equated for brightness at $1.5 \mathrm{ft}-\mathrm{L}$.

Six paid Ss with normal color and acuity vision served in this experiment. Pilot research was conducted in which identification thresholds were obtained for all Ss for all letters of the four hues with left and right eyes. Nonparametric analyses of the data revealed no significant differences attributable to letters or viewing eyes. Significant differences were obtained for hues and Ss. Further pilot work indicated that $40 \%-60 \%$ masking occurred when the target stimulus, followed after a $35-\mathrm{msec}$ dark interstimulus interval by a $200-\mathrm{msec}$ mask, was presented for a duration of $20 \mathrm{msec}$ above threshold. Accordingly, the target stimuli durations were set at $20 \mathrm{msec}$ above each S's threshold for identification of letters of each of the four hues. The unilluminated interstimulus interval was set at a constant $35 \mathrm{msec}$. The temporal duration of the mask was fixed at $200 \mathrm{msec}$. Each trial, then, consisted of the following: (1) fixation field, (2) verbal ready signal, (3) presentation of target, (4) interstimulus interval, (5) mask, (6) reappearance of fixation field, and (7) S's response, i.e., identification of letter if perceived. There were 18 trials for each of the conditions comprising a total of 1152 measures for each of the Ss.

\section{RESULTS AND DISCUSSION}

The data (number of correct identifications for each condition) were treated in an analysis of variance. The results of this analysis showed a significant difference in masking for the monoptic and dichoptic viewing conditions $(F=10.23$, $\mathrm{df}=1 / 6, \mathrm{p}<.05)$. The mean number of correctly identified letters of all hues with monoptic presentation of target and mask was 9.23 . For dichoptic presentations the 
Table 1

Mean Masking Effect of All Mask Hues on Each Target Hue

\begin{tabular}{|c|c|c|c|c|c|c|}
\hline \multirow[b]{3}{*}{ No. } & \multirow[b]{3}{*}{ Target Hue } & \multicolumn{5}{|c|}{ Means, Mean Differences, $t$ Tests* } \\
\hline & & \multirow{2}{*}{$\begin{array}{l}\text { Mean Number } \\
\text { of Correct } \\
\text { Identifications }\end{array}$} & \multicolumn{4}{|c|}{ Mean Differences } \\
\hline & & & 1 & 2 & 3 & 4 \\
\hline 1 & Red & 12.250 & - & .547 & 3.125 & 8.109 \\
\hline 2 & Blue & 12.797 & & - & 3.672 & 8.656 \\
\hline 3 & Green & 9.125 & & & - & 4.984 \\
\hline 4 & Yellow & 4.141 & & & & - \\
\hline
\end{tabular}

* The tukey method was used to determine the differences between means necessary for significance. Mean differences required for significance: $3.33(p=.05) ; 4.78(p=.01)$.

Table 2

Mean Masking Effect of Each Mask Hue on All Target Hues

\begin{tabular}{|c|c|c|c|c|c|c|}
\hline \multirow[b]{3}{*}{ No. } & \multirow[b]{3}{*}{ Mask Hue } & \multicolumn{5}{|c|}{ Means, Mean Differences, and t Tests* } \\
\hline & & \multirow{2}{*}{$\begin{array}{c}\text { Mean Number } \\
\text { of Correct } \\
\text { Identifications }\end{array}$} & \multicolumn{4}{|c|}{ Mean Differences } \\
\hline & & & 1 & 2 & 3 & 4 \\
\hline 1 & Red & 9.266 & - & .328 & .625 & .953 \\
\hline 2 & Blue & 8.938 & & - & .953 & 1.281 \\
\hline 3 & Green & 9.891 & & & - & .328 \\
\hline 4 & Yellow & 10.219 & & & & - \\
\hline
\end{tabular}

* The Tukey method was used to determine the differences between means necessary for significance. Mean differences required for significance: $.840(p=.05) ; 1.07(p=.01)$.

mean number of correct identifications was 9.92. This small but statistically significant difference of $4 \%$ in masking under the two modes of stimulus presentation indicates that, while masking by hue occurs at both central and peripheral loci in the visual system, inhibition of target identification is most effective with central mediation.

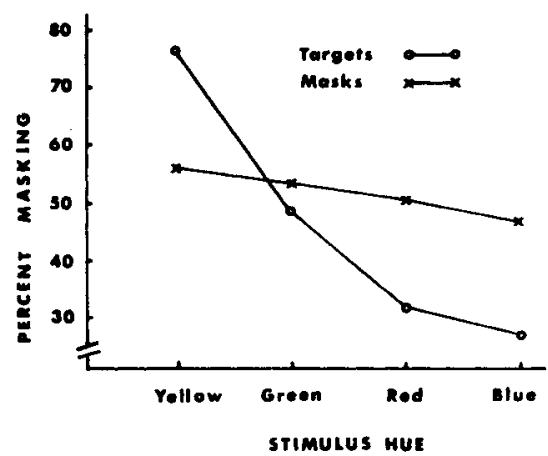

Fig. 1. Amount of masking expressed in percentages for the four target hues averaged for all masks and for the four mask hues averaged for targets.

Another finding of this experiment was that significant portions of the variance were attributable to differences in target $(F=75.15, \mathrm{df}=1 / 6, \mathrm{p}<.01)$ and mask $(F=7.33, \mathrm{df}=3 / 18, \mathrm{p}<.01)$ hue. Table 1 presents the mean number of correct identifications for each of the four target hues and the results of $t$ tests for all pairs of means. An examination of this table shows the four hues to be ordered in terms of their resistance to masking effects from blue, red, green, to yellow. The $t$ tests among the target means indicate that all mean differences are statistically significant with the exception of the red-blue and red-green comparisons. In sum, blue is the most efficient hue in terms of maximizing S's resistance to masking effects. Red and green are intermediate and yellow is the most readily masked stimulus hue. Similar findings for mask hues may be seen in Table 2. The four mask hues were found to be ordered from blue, red, green, to yellow in terms of their average masking effect on all target stimuli (here the lower the number the more effective is the hue in masking). An examination of the results of the tests shows that the significant main effect for mask hue is due to the blue-green, blue-yellow, and red-yellow mean differences. Figure 1 presents the data in terms of per cent masking for each of the four target and mask hues. The probability of correct identification of the letters decreases from a maximum with blue targets through red and green to a minimum with yellow targets. Conversely, the probability of correct identification decreases from a maximum with yellow masks through green and red to a minimum with blue masks.

In conclusion, the results of this experiment support earlier findings of chromatic backward masking. When brightness contrast between target and mask figures and background is eliminated and brightness and saturation values for target and mask stimuli are held constant, masking by hue may occur. The extent of masking varies significantly with the particular target and mask hues employed. Masking by hue may occur under both monoptic and dichoptic conditions of stimulus presentation with dichoptic conditions producing significantly more inhibition of target stimulus identification.

\section{REFERENCES}

ALPERN, M. Metacontrast: Historical introduction. American Journal of Optometry, 1952, 29, 631-646.

ALPERN, M. Metacontrast. Journal of the Optical Society of America, 1953, 43, 648-657.

ERICKSEN, C. W., \& HOFFMAN, M. Form recognition at brief durations as a function of adapting field and interval between stimulations. Journal of Experimental Psychology, 1963, 66, 485-499.

KOLERS, P. A. Intensity and contour effects in visual masking. Vision Research, 1962, 2 277-294.

RAAB, D. H. Backward masking. Psychological Bulletin, 1963, 69,118-129.

SCHILLER, P. H. Monoptic and dichoptic visual masking by patterns and flashes. Journal of Experimental Psychology, 1965, 69, 193-199.

SCHILLER, P. H., \& WIENER, M. Monoptic and dichoptic visual masking. Journal of Experimental Psychology, 1963, 66, 386-393.

WERNER, H. Studies on contour: I. Qualitative analysis. American Joumal of Psychology, $1935,47,40-64$.

\section{NOTE}

1. Supported in part by NIH Grant M-3860 and NIH Predoctoral Fellowship MH-21504. 